\title{
Treatment of uncomplicated gonorrhoea with rosoxacin (acrosoxacin)
}

\author{
K B LIM, V S RAJAN (Deceased), Y C GIAM, E O LUI, E H SNG, AND K L YEO \\ From Middle Road Hospital, Singapore 0718, Singapore
}

SUMMARY An open study was designed primarily to evaluate the efficacy of rosoxacin in the treatment of gonorrhoea caused by penicillinase producing Neisseria gonorrhoeae (PPNG) and non-PPNG strains. A total of 199 patients (99 men and 100 women) satisfactorily completed follow up examinations, 50 men and 50 women having received rosoxacin $300 \mathrm{mg}$ orally and the remainder having received kanamycin $2 \mathrm{~g}$ intramuscularly. Rosoxacin achieved an overall cure rate of $94 \%$ (96.7\% for PPNG and $90 \%$ for non-PPNG strains). In patients treated with kanamycin the overall cure rate was $89.9 \%(92 \cdot 7 \%$ for PPNG and $83 \cdot 3 \%$ for non-PPNG strains). A correlation between treatment failures and minimum inhibitory concentrations (MICs) of rosoxacin was noted in non-PPNG strains but not in PPNG strains. Side effects which were mild and self limiting were noted in 15 of 100 patients treated with rosoxacin. The high failure rates associated with non-PPNG strains requiring MICs of $0.125 \mathrm{mg} / \mathrm{l}$ and the observation of a substantial rise in the MICs for isolates after treatment is of concern. Otherwise, rosoxacin in a single dose of $300 \mathrm{mg}$ appears to be safe and effective for the treatment of uncomplicated gonorrhoea.

\section{Introduction}

Gonococcal strains, especially those in the Far East, have been able to develop increasing levels of resistance to penicillin. This has been further complicated by the emergence of penicillinase producing Neisseria gonorrhoeae (PPNG) strains, which were first isolated in Singapore in 1976. Since then PPNG strains have become endemic, and in 1982 accounted for 2413 cases or $34 \cdot 5 \%$ of all gonococcal isolates in Singapore. Like many countries in the Far East, Singapore has witnessed increasing failure rates with penicillin, and there is a constant need to evaluate new antimicrobials.

Rosoxacin is a quinolone antimicrobial agent structurally related to nalidixic acid. In vitro tests have confirmed that rosoxacin has potent activity against a broad spectrum of Gram negative bacteria including $N$ gonorrhoeae. It is well absorbed by the oral route, with serum concentrations reaching $6.2 \mathrm{mg} / \mathrm{l}$ one hour after a single $300 \mathrm{mg}$ dose. ${ }^{1}$ This is well above the reported minimum inhibitory concentrations (MICs) of $0 \cdot 015-0 \cdot 125 \mathrm{mg} / \mathrm{l}$ for PPNG and non-PPNG strains. ${ }^{2}$

Address for reprints: Dr K B Lim, Middle Road Hospital, 250 Middle Road, Singapore 0718, Republic of Singapore

Accepted for publication 9 November 1983
This study was designed to determine the efficacy of rosoxacin in the treatment of PPNG and nonPPNG infections. Comparisons were made with patients treated with kanamycin, an agent used commonly in Singapore for the treatment of gonorrhoea.

\section{Patients and methods}

\section{STUDY POPULATION}

Two hundred patients with acute gonorrhoea (100 men and 100 female prostitutes) were included in the trial. Patients with a history of hypersensitivity to quinolone and azaquinolone drugs, renal disease, urinary tract obstruction, liver and biliary disease, central nervous system disease, gastrointestinal disease, disseminated gonococcal infections, uncontrolled diabetes mellitus, or serious haemopoietic disease were excluded. Pregnant women and patients who had received antimicrobial treatment less than 72 hours before the start of the trial were also excluded.

\section{DIAGNOSES}

Gonorrhoea was diagnosed on the finding of Gram negative intracellular diplococci in stained smears or on the isolation of $N$ gonorrhoeae on culture, or on both. Men whose urethral smears gave positive 
results were entered into the trial. All diagnoses were confirmed by culture and included infections caused by PPNG and non-PPNG strains. Only women with gonococcal cervicitis due to PPNG strains were recruited into the study. Gonococcal isolates were identified by their colonial morphology on modified Thayer-Martin medium, oxidase reaction, and Gram stained microscopical appearance. 'Penicillinase production was tested for in all isolates by the paper acidometric method. ${ }^{3}$

\section{TREATMENT}

Fifty men and 50 women received a single $300 \mathrm{mg}$ dose (two $150 \mathrm{mg}$ capsules) of rosoxacin while the remaining 100 patients received $2 \mathrm{~g}$ of kanamycin in a single intramuscular injection.

\section{FOLLOW UP AND TESTS OF CURE}

The patients were assessed on day 3 or 4 and day 14 after treatment. Urethral smears and cultures were obtained from the men and only cervical cultures from the women at each visit. Treatment was considered to have failed if the culture gave positive results on day 3 or 4 and the patient denied further sexual intercourse. If gonococci were isolated on day 14 and the patient admitted sexual intercourse reinfection was assumed to have occurred. Serum was tested for cardiolipin antibodies, using the Venereal Diseases Research Laboratory (VDRL) test, before and six weeks and three months after treatment.

\section{Results}

\section{TREATMENT RESPONSE}

Table I shows the details of treatment response. One man did not attend for follow up tests and was excluded from the study, leaving 99 men and 100 women for assessment.

The overall cure rate with rosoxacin was $94 \%$ (96.7\% for PPNG and $\mathbf{9 0 \%}$ for non-PPNG strains) while the overall cure rate with kanamycin was
$89.9 \%(92.7 \%$ for PPNG and $83.3 \%$ for nonPPNG strains). Although rosoxacin achieved a better overall cure rate than kanamycin, the difference was not significant $\left(\chi^{2}=0 \cdot 64 ; 0 \cdot 5>p>0 \cdot 1\right)$. The numbers involved, however, were small. Rosoxacin was also more successful in eradicating PPNG infections in women ( $98 \%$ cure rate) than in men ( $90 \%$ cure rate), the reason for which is not clear.

\section{SIDE EFFECTS}

Side effects were reported by 15 of the 100 patients treated with rosoxacin; 12 complained of dizziness, one of malaise, one of drowsiness, and one of gastritis. All these side effects were mild and transient.

\section{ANTIBIOTIC SUSCEPTIBILITY}

Antibiotic susceptibility tests were performed on 129 PPNG and 70 non-PPNG isolates. The MICs of rosoxacin were measured by the agar plate dilution method described previously. ${ }^{4}$ Table II shows that the range of MICs was identical $(0 \cdot 008-0 \cdot 125 \mathrm{mg} / \mathrm{l})$ for PPNG and non-PPNG strains. Their geometric means were 0.0304 and $0.03525 \mathrm{mg} / 1$ respectively.

TABLE II Number of strains of $N$ gonorrhoeae inhibited by various concentrations of rosoxacin

\begin{tabular}{llllll}
\hline & \multicolumn{4}{l}{$\begin{array}{l}\text { Minimum inhibitory } \\
(\mathrm{mg} / \mathrm{l}):\end{array}$} & concentrations \\
\cline { 2 - 6 } Strains & 0.008 & 0.016 & 0.03 & 0.06 & 0.125 \\
\hline PPNG (n=129) & 9 & 10 & 27 & 59 & 24 \\
Non-PPNG $(\mathrm{n}=70)$ & 6 & 14 & 17 & 26 & 7 \\
\hline
\end{tabular}

We examined the MICs of rosoxacin and benzyl penicillin for 29 PPNG and 70 non-PPNG isolates. When all isolates were considered together, correlation between the MICs of both agents was poor (correlation coefficient $(r)=0 \cdot 24)$. The correlation was equally poor when PPNG and nonPPNG isolates were considered separately $(r=0.26$ and $0 \cdot 18$ respectively).

TABLE I Treatment response of 99 men and 100 women $(29$ men and all women infected with PPNG strains to rosoxacin or kanamycin

\begin{tabular}{|c|c|c|c|c|c|c|}
\hline \multirow[b]{2}{*}{ Treatment } & \multirow[b]{2}{*}{ Strains } & \multicolumn{3}{|c|}{ No $(\%)$ cured } & \multicolumn{2}{|c|}{ No $(\%)$ treatment failure } \\
\hline & & Men & Women & Total & Men & Women \\
\hline \multirow[t]{2}{*}{$\begin{array}{l}\text { Rosoxacin } \\
300 \mathrm{mg}\end{array}$} & $\begin{array}{l}\text { PPNG }(n=10 \mathrm{~m}, 50 \mathrm{f}) \\
\text { Non-PPNG }(n=40 \mathrm{~m})\end{array}$ & $\begin{array}{r}9(90 \cdot 0) \\
36(90 \cdot 0)\end{array}$ & $\begin{array}{l}49(98 \cdot 0) \\
0\end{array}$ & $\begin{array}{l}58(96 \cdot 7) \\
36(90 \cdot 0)\end{array}$ & $\begin{array}{l}1(10 \cdot 0) \\
4(10 \cdot 0)\end{array}$ & $\begin{array}{l}1(2 \cdot 0) \\
0\end{array}$ \\
\hline & Total $(n=100)$ & & & $94(94 \cdot 0)$ & & \\
\hline \multirow[t]{2}{*}{$\begin{array}{l}\text { Kanamycin } \\
2 \mathrm{~g}\end{array}$} & $\begin{array}{l}\text { PPNG }(n=19 \mathrm{~m}, 50 \mathrm{f}) \\
\text { Non-PPNG }(\mathrm{n}=30 \mathrm{~m})\end{array}$ & $\begin{array}{l}16(84 \cdot 2) \\
25(83 \cdot 3)\end{array}$ & $\begin{array}{l}48(96 \cdot 0) \\
0\end{array}$ & $\begin{array}{l}64(92 \cdot 7) \\
25(83 \cdot 3)\end{array}$ & $\begin{array}{l}3(15 \cdot 7) \\
5(16 \cdot 7)\end{array}$ & $\begin{array}{l}2(4 \cdot 0) \\
0\end{array}$ \\
\hline & Total $(n=99)$ & & & $89(89 \cdot 9)$ & & \\
\hline
\end{tabular}


Table III shows the results of rosoxacin treatment and the MICs for gonococcal isolates from 40 of the men treated with rosoxacin. Treatment failed to eradicate three $(\mathbf{4 3 \%})$ of seven non-PPNG strains with MICs of $0.125 \mathrm{mg} / \mathrm{l}$ compared with one $(3 \%)$ of 33 non-PPNG strains with MICs of 0.008-0.06 mg/l.

TABLE III Correlation of in vitro susceptibility of nonPPNG isolates from 40 men and in vivo response to rosoxacin (percentages in parentheses)

\begin{tabular}{llr}
\hline $\begin{array}{l}\text { Response to } \\
\text { treatment }\end{array}$ & \multicolumn{1}{c}{ Minimum inhibitory concentrations $(m g / l):$} \\
\cline { 2 - 3 } & $0 \cdot 125$ & $0 \cdot 008-0.06$ \\
\hline $\begin{array}{l}\text { Success } \\
\text { Failure }\end{array}$ & $4(57 \cdot 1)$ & $32(97 \cdot 0)$ \\
$1(42 \cdot 9)$ & $(3 \cdot 0)$ \\
\hline
\end{tabular}

The correlation between treatment response and the MICs of non-PPNG strains is further illustrated in the figure. Such a correlation did not emerge when we examined the MICs of PPNG isolates from the remaining 10 men and 50 women (see table IV).

We measured MICs for isolates obtained after treatment from patients who were treatment failures. Two isolates showed a significant rise in the MIC: one (a non-PPNG strain) showed an increase from $0.125 \mathrm{mg} / \mathrm{l}$ before treatment to $4 \mathrm{mg} / \mathrm{l}$ after treatment, and another (a PPNG strain) showed an increase from $0.06 \mathrm{mg} / 1$ to $2 \mathrm{mg} / \mathrm{l}$.

\section{Discussion}

The ability of gonococci to evolve into more resistant strains and the emergence of penicillinase producing strains emphasise the need to evaluate new

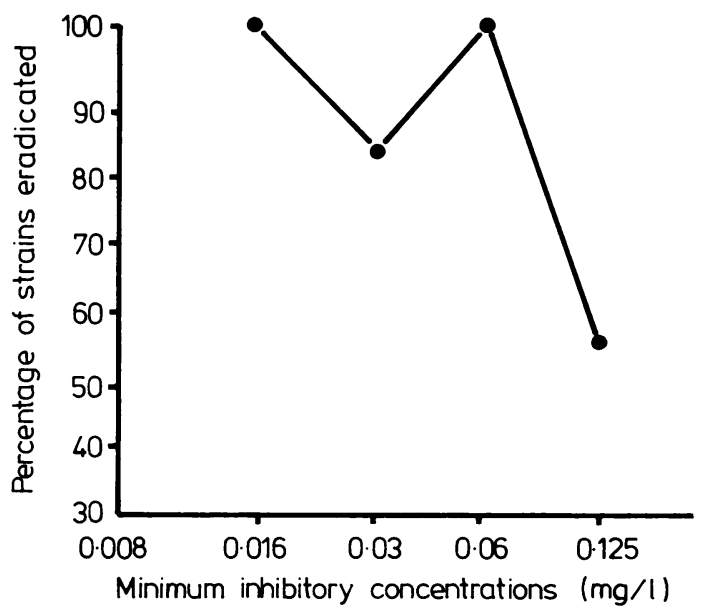

FIGURE Correlation of in vitro susceptibility of nonPPNG strains and response to rosoxacin.
TABLE IV Correlation of in vitro susceptibility of PPNG isolates from 10 men and 50 women and in vivo response to rosoxacin (percentages in parentheses)

\begin{tabular}{|c|c|c|}
\hline \multirow{2}{*}{$\begin{array}{l}\text { Response to } \\
\text { treatment }\end{array}$} & \multicolumn{2}{|c|}{ Minimum inhibitory concentrations ( $\mathrm{mg} / \mathrm{l})$ : } \\
\hline & $0 \cdot 125$ & $0.008-0.06$ \\
\hline $\begin{array}{l}\text { Success } \\
\text { (Men) } \\
\text { (Women) }\end{array}$ & $\left.\begin{array}{r}3 \\
11\end{array}\right\} 14(100)$ & $\left.\begin{array}{r}6 \\
38\end{array}\right\} 44(95 \cdot 7)$ \\
\hline $\begin{array}{l}\text { Failure } \\
\text { (Men) } \\
\text { (Women) }\end{array}$ & $\left.\begin{array}{l}0 \\
0\end{array}\right\} 0$ & $\left.\begin{array}{l}1 \\
1\end{array}\right\} 2(4 \cdot 3)$ \\
\hline
\end{tabular}

antimicrobial agents. Owing to variations in the antimicrobial susceptibility of strains between regions, an antimicrobial agent shown to be effective in clinical trials conducted in one region still needs to be evaluated in the population for which it is intended before its use can be recommended. Many antibiotics, such as tetracyclines and co-trimoxazole, which were found to be effective in the treatment of gonorrhoea in other countries have been found to be less effective in Singapore. ${ }^{5}$

In this study, an overall cure rate of $94 \%$ was obtained with rosoxacin, which eradicated $96 \cdot 7 \%$ of infections caused by PPNG strains and $90 \%$ caused by non-PPNG strains. Comparable results have been reported, with overall cure rates of $94-100 \%$ using similar doses of rosoxacin. .-10 $^{-1}$

Handsfield et al reported that treatment with rosoxacin failed to eradicate all three non-PPNG strains that required MICs of $\geqslant 0.125 \mathrm{mg} / 1 .{ }^{6}$ The patients whose isolates required MICs of $0.125 \mathrm{mg} / \mathrm{l}$ and $1.0 \mathrm{mg} / \mathrm{l}$ were each treated with $100 \mathrm{mg}$ of rosoxacin while the remaining patient infected with an isolate requiring an MIC of $0.25 \mathrm{mg} / 1$ received $400 \mathrm{mg}$ of rosoxacin. Although the dosages used are different from those used in this study, our results and theirs suggest that non-PPNG strains requiring MICs of $0.125 \mathrm{mg} / 1$ or higher may be resistant. Warren et al found a good correlation between the MICs of benzyl penicillin and rosoxacin for isolates moderately resistant to penicillin (MICs of benzyl penicillin of $0 \cdot 06-1 \mathrm{mg} / \mathrm{l}),{ }^{11}$ and suggested that the penetration barrier of gonococci moderately resistant to penicillin may also be effective to some extent against rosoxacin. Our results, however, showed that there was little correlation between the MICs of the two agents. Nevertheless, a penetration barrier to rosoxacin exists, though this may be distinct from that effective against penicillin. Penetration may be improved by using larger or additional doses of rosoxacin. Further studies would be necessary to evaluate the efficacy of such regimens. Our results also suggest that PPNG strains in Singapore are more susceptible to rosoxacin regardless of the MICs. 
This study confirms that rosoxacin has good overall efficacy against $N$ gonorrhoeae. Rosoxacin permits simple, single dose oral treatment and is well tolerated. Side effects were mild and transient, but nevertheless, patients should be warned about them. One observation which caused some concern was a significant rise in the MIC for isolates obtained after treatment from two patients whose treatment had failed. All patients whose treatment failed were interviewed again and although we cannot absolutely exclude the possibility of reinfection, we felt it was unlikely for the following reasons. The first follow up test was performed only $\mathbf{7 2}$ hours after treatment. Secondly, the patients were interviewed again and reminded of the objectives of this study and the importance of truthfulness, and we therefore have no reason to doubt their word. We were not, however, able to serotype the strains and therefore it was impossible to ascertain whether the increase in MIC represented selection of more resistant clones or induction of resistance. The possible mechanism should be investigated.

In conclusion, the use of rosoxacin may be considered in areas where PPNG strains are prevalent, but its use should be limited to centres with good follow up facilities.

We thank Sterling Drugs (Singapore) Private Limited (Winthrop Division) for making this study possible.

\section{References}

1. Bro-Jorgensen A, Jensen T. Single dose oral treatment of gonorrhoea in men and women using ampicillin alone and combined with probenecid. Br J Vener Dis 1971;47:443-7.

2. Seth AD. Sensitivity of gonococci to rosoxacin compared to that of penicillin, cefuroxime and tetracycline. $J$ Antimicrob Chemother 1981;7:331-4.

3. Sng EH, Yeo KL, Rajan VS. Simple method for detecting penicillinase-producing Neisseria gonorrhoeae and Staphylococcus aureus. Br J Vener Dis 1981;57:141-2.

4. Sng EH, Rajan VS, Pang R, Yeo KL. Susceptibility of Neisseria gonorrhoeae to cefotaxime and ceftizoxime. $B r J$ Vener Dis 1981;57: 162-4.

5. Rajan VS, Tan NJ, Tan T, Khoo R, Sng EH, Pang CP. Treatment of gonorrhoea: the Singapore experience. Asian Journal of Infectious Diseases 1971;1:71-4.

6. Handsfield HH, Judson FN, Holmes KK. Treatment of uncomplicated gonorrhoea with rosoxacin. Antimicrob Agents Chemother 1981;50:625-9.

7. Woscoff A, Flichman JC, Man F, et al. Rosoxacin (Win 35213) in the treatment of uncomplicated acute gonococcal infection. Clin Ther 1982; 4:515-25.

8. Soendjojo A, Hudiodo It, Idajadi A, Barakbar Y. Rosoxacin, a new agent for the treatment of gonorrhoea. Asian Journal of Clinical Sciences 1982;1:34-6.

9. Limson BM, Macasaet RK. Single oral dose rosoxacin in the treatment of gonorrhoea in males. J Int Med Res 1982; 10:42-5.

10. Calubiran OV, Crisologo-Vizconde LB, Tupasi TE, Torres CA, Limson BM. Treatment of uncomplicated gonorrhoea in women-comparison of rosoxacin and spectinomycin. $\mathrm{Br} J$ Vener Dis 1982;58:231-5.

11. Warren CA, Shannon KP, Phillips I. In-vitro antigonococcal activity of rosoxacin (WIN 35213). Br J Vener Dis 1981; 57:33-5. 